\title{
Impacts of Extended Working Hours in Logging
}

\author{
Dana Mitchell, PhD, Research Engineer \\ USDA Forest Service, Southern Research Station, 520 Devall Drive, Auburn, AL 36849, \\ danamitchell@fs.fed.us
}

\section{Tom Gallagher, PhD, Assistant Professor}

School of Forestry and Wildlife Sciences, Auburn University, Auburn, AL 36849, tgallagher@auburn.edu

\author{
Written for presentation at the \\ 2008 ASABE Annual International Meeting \\ Sponsored by ASABE \\ Rhode Island Convention Center \\ Providence, Rhode Island \\ June 29 - July 2, 2008
}

\begin{abstract}
Last year at the 2007 AIM in Minneapolis, MN, the authors presented the human factors impacts to consider when implementing extended working hours in the logging industry. In a continuation of this project, we have researched existing literature to identify possible actions that logging business owners can take to reduce the impact of extended working hours on their employees. Fatigue and mental burnout associated with working long shifts may be reduced by scheduling two or more substantial rest breaks during a shift. Seated exercises or short breaks where operators dismount equipment may relieve the physical impacts of sedentary machine operation. Encouraging employees to try alternative sleep schedules may help workers adjust to late shift working hours. Safety plans should be revised to provide better communication between machine operators during the late shift, and to address additional personal protective equipment for late shift workers. Interviews for hiring new employees should include questions that are structured to find personality traits that may help identify applicants that are more suited for the late shift. Social impacts of permanent late shift assignments may be reduced by offering a flexible schedule where employees can change schedules when needed. Human factors impacts of implementing extended working hours in logging is often overlooked, with the majority of the early planning focused on the financial aspects of implementation. The results of this study may be useful to those considering implementing extended working hours and also to those who have already begun implementation.
\end{abstract}

Keywords. shift work, logging, forest workers, extended working hours, human factors. 


\section{Introduction}

Some logging business owners in the southeastern United States have implemented extended working hours for their logging crew operations. Their reasons vary, but are often centered on increasing production. Most business owners implement extended working hours by operating one set of equipment for more than one shift. By increasing the scheduled hours for operating a set of equipment, business owners hope to spread the cost of equipment ownership across more production.

A variety of shift schedules have been used (Mitchell and Gallagher, 2007) by logging business owners in seven southeastern states. Schedules included various number of days worked/week depending on which shift is worked, rotating shifts versus permanent assignment to a particular shift, and even shift length differences between day and late shifts. The decision to implement extended working schedules is further complicated by operational characteristics, such as which equipment is operated during the late shift; tract availability; and mill delivery quotas.

Extended working hour schedules could potentially have a negative impact on the goal of increased production. Shift work can cause psychological, physiological and even social impacts on employees. Some of these impacts may result in higher employee turnover, decreased safety, or decreased work performance. Increased turnover not only leads to understaffed operations, but it can lead to lower production while new employees gain the knowledge, skills and abilities needed to fulfill their job duties. Decreased work performance may negatively impact logging costs. The objective of this paper is to offer suggestions of human factors topics to consider before implementing extended work schedules.

\section{Data Collection/Methodology}

Semi-structured interviews were performed to gather information about how logging business owners were implementing extended working hour schedules in seven southeastern states. A face-to-face interview method was selected because more in-depth information can usually be attained in person, as opposed to telephone calls or through mail surveys. The interview process began in the spring of 2006. Twenty-two interviews were completed with logging business owners who have made efforts to implement shift work. Selection of interviewees was not random. Logging business owners were selected for interviewing because they had tried or were currently using shift work. Logging business owners to be interviewed were found by referring to trade journal articles, contacting state forestry and forest industry representatives, and through discussions with loggers and others at regional forestry-related meetings. In addition, some logging business owners were found through contacts with other loggers that were implementing extended working schedules. Therefore, this was a $100 \%$ sampling of those logging business owners that could be identified. The bulk of the logging business owners interviewed were preferred suppliers for large timber industries.

The interview questions were used as a guide, and some of the discussions led away from the topics and provided some additional insightful information. Generally, interviews lasted for one hour. Interviews were held in the woods, at restaurants, and at business offices over the course of 18 months. Data collected during the interviews included employee turnover, shift hours, shift scheduling, and safety considerations. Most of the owners operated their ground-based systems in fairly flat terrain, consisting mostly of various types of southern pine trees. 


\section{Results and Discussion}

\section{Shift Length}

A variety of shift hours have been used by logging business owners. Five tried working two 12hour shifts in a 24-hour period. Three of those subsequently quit using shift work. Another logging business owner uses a single 12-hour shift, 7 days/week. In general, for those using two shifts/day, the day shift lengths reported were longer than the night shift lengths. The day shift length ranged from 8 to 12 hours, including meal and rest breaks. The average day shift length was 10.4 hours. The night shift lengths ranged from 7.5 to 12 hours with an average of 9.5 hours.

Long shifts can lead to fatigue and mental burnout. One proposed response to minimize the effects of long shifts is to offer two or more substantial rest breaks evenly spread throughout the shift. Performance levels may be maintained by scheduling rest breaks (Kirk, 1998).

Long shifts can lead to illness due to lack of physical body exercise (Berger, 2003). Impacts can include weakened immune systems, sore neck muscles from bracing, and increased blood sugar. Frequent, short breaks where operators dismount equipment can introduce movement into muscle groups that aren't used when operating equipment (Sullman and Kirk, 1998). These short breaks may result in fewer work days missed due to illness. The American Physical Therapy Association (APTA, 2008) recommends several exercises that can be performed from a seated position. The exercises keep blood flowing, the joints mobile, and the muscles relaxed. Although the exercises are recommended for airplane passengers, they could be applied to late shift forestry workers to introduce movement into muscle groups without exiting the safety of the machine's protective structure.

\section{Shift Hours}

Working nights can disrupt circadian rhythms. The typical circadian low occurs between 0300 and 0500. Sixteen logging business owners implemented extended working hours by scheduling two shifts per day for a total of less than 24 hours/day. Twelve of these completed their work schedule by 0100 (Table 1). The remaining four business owners ended their work schedules after 0100 . The majority, $89 \%$, of those that continued implementing extended working hours ended their work schedules by 0100 . However, of those logging business owners that quit implementing extended working hours, $43 \%$ ended their schedule after 0100. Ending clock hours before 0100 may contribute to the success of implementing extended working hours.

Table 1. Ending clock hours for schedules using two shifts and less than 24 working hours/day.

\begin{tabular}{ccc}
\hline & \multicolumn{2}{c}{ Current Status } \\
\cline { 2 - 3 } Ending Clock Hour & Quit Shift Work & $\begin{array}{c}\text { Currently Implementing } \\
\text { Shift Work }\end{array}$ \\
\hline$\leq 2300$ & 1 & 4 \\
2400 & 1 & 1 \\
0100 & 2 & 3 \\
0200 & 3 & 0 \\
0300 & 0 & 1 \\
\hline Totals & 7 & 9 \\
\hline
\end{tabular}

Although most of the business owners implementing more than one shift/day and fewer than 24 hours/day did not schedule work during the typical circadian low hours, their workers could have 
been commuting during the early morning hours between 0300 and 0500 . This could pose a potential accident risk. Many studies report that sleepiness reduces vigilance while driving and increases the risk of a motor vehicle collision (MacLean et al, 2003; George, 2003; and Philip and Akerstedt, 2006). Some of the most common changes in driving performance related to sleepiness are increased variability of speed and lateral lane position. The prepared interview questions did not specifically address this potential risk. The interviews were semi-structured so that this type of information could have been offered, but workers may be reluctant to report vehicle accidents that occurred during off-duty hours.

\section{Psychological}

Personality traits seem to play a major role in worker's ability to adapt to shift work. Furnham and Hughes (1999) found that night shift television crew workers reported lower levels of job satisfaction than day workers. Extroverts may fare better working as a team during the day shift where they can rally support from others, rather than working alone on a particular task. However, the workers with an introvert-type personality seem to fare better on night shifts than those with an extrovert type of personality.

While a logging operation works together on one tract, individual workers on a logging crew typically work alone. The feller-buncher operator fells trees ahead of the skidder operation, so interaction between operators is typically limited but they are aware of each other's location. Because each worker is in an enclosed equipment cab, interactions are further limited. With this limited interaction between co-workers, night workers may feel even more isolated due to the absence of sunlight. As Furnham and Hughes (1999) suggest, perhaps workers with an introvert type of personality would fare better during the night shift than those with an extrovert type of personality.

Difficulties associated with personality traits and working independently may be further exacerbated by the smaller crew size on the late shift logging crews. Logging business owners reported running their operations during the late shift differently than the day shift. Some activities, such as felling or hauling, were often performed only during the day shift. Therefore, the late shift was, on average, half the size of the day shift crew.

Many of the logging business owners interviewed reported that some of their workers prefer the night shift because there were fewer people on the job site at night, as contract administrators, foresters, and others work daytime hours. When fewer workers are on site, operators experience lower mental stress levels because man and machine interferences are reduced (Kirk, 1998). During hiring interviews, attempts to gain insight for the introvert or extrovert personality style of potential new employees may help reduce worker turnover associated with implementing extended working hours.

\section{Sleep Schedules}

People often find it difficult to adjust to shift schedules that include working the hours between 0300 and 0500 . If work must be scheduled during the circadian lows, some workers may be more tolerant of this schedule than others. For example, people commonly referred to as "nightowls" normally go to bed later than others, so they delay their sleep. Adjustment to night work may not be as difficult for these people as for others (Burgess et al, 2002). So, sleep patterns could be helpful in determining which employees may be more capable of adapting to working the late shift.

The rate of sleep complaints is higher in shift workers than in the general population (Ohayon et al, 2002). The main sleep period for shift workers can be from 1 to 4 hours shorter than typical 
night sleep schedules. There are factors, other than circadian rhythms, that can cause deterioration of sleep quality: fatigue, stress, daylight, health and age. Problems from working rotating shifts can arise with the length of time it takes to fall asleep, inability to wake up at the time desired, and disrupted sleep (nocturnal awakenings).

When implementing extended working schedules, workers should be encouraged to try different sleep schedules. These may include sleeping for 8 hours either immediately after, or immediately before (extended awakening), the late shift (Santhi et al, 2005).

Employee interviews for late shift work should include questions structured to find traits that may be more suited to the late shift hours. Questions and discussions could attempt to decide whether an applicant is a "night-owl" or if they are more of an introvert-type of personality. Workers with either of these traits have been identified as being more suited to late shift hours.

\section{Social Impacts}

Research shows that workers with rotating shifts (including weekends) will experience more job dissatisfaction than even those with fixed non-day schedules (Demerouti et al, 2004). Those on fixed schedules report higher job satisfaction, professional efficacy and lower cynicism and lower turnover rates than those on rotating shifts. High levels of work-home conflict are reported by workers with permanent late shift assignments (Demerouti et al, 2004).

In this study, only two logging business owners offered working schedules that rotate between day and late shifts. Eighteen implemented permanent late shift assignments. Of the remaining two logging business owners interviewed, one offered a schedule of 12 hours/day, 7 days/week. The other offered extended hours on a daily basis with daily self-selection for the late shift hours. Only two logging business owners regularly scheduled work on Saturday or Sunday.

There may be social impacts of implementing extended work schedules. Logging business owners implementing extended working hours may consider offering a fixed shift assignment schedule with flexibility added where workers can switch schedules amongst themselves to allow participation in family and other social activities. Many logging business owners allowed their employees to self-select working shifts when first implementing extended working schedules. Some workers chose the late shift for family reasons, while others preferred working at night to limit their interactions with others. By offering a fixed-but-flexible schedule, employees may have higher job satisfaction and lower turnover rates, and the added flexibility may help reduce work-home conflicts associated with permanent late shift assignments.

\section{Safety}

Typically, the most experienced, highest seniority employees are assigned to the day shift (Penkala, 1994). As mentioned earlier, logging business owners reported that their employees were allowed to self-select for day or late shifts when they first implemented extended working hour schedules. This typically resulted in the most experienced employees working the day shift and the late shift was generally comprised of the least experienced employees and new employees. Staffing levels at night were often less than during the day shift, so some night workers may take more chances and perform jobs for which they are unqualified in order to maintain night production.

Employees may miss safety meetings due to shift schedules (Penkaka, 1994). Logging business owners need to consider their safety meeting schedules so that workers from all shifts are exposed to the same information. 
Fatigue may be associated with compromised safety (Berger, 2003; Sullman and Kirk, 1998). Many of the logging business owners in this study improved their communication devices and safety plans in consideration of working longer hours and/or after dark. In addition to added equipment lighting, some of the improvements included headlights mounted on hard hats, highvisibility vests, and adding two-way radios in machines. Other actions included steps to take when an employee exits a vehicle at night. Some logging businesses changed their safety plan to include stopping all machines when an employee exits a machine after dark, and requiring radio communications between machine operators when one leaves the safety of the cab at night. None of the logging business experienced any employee accidents or injuries on the late shift.

\section{Conclusion}

In twenty-two interviews with logging company owners, a variety of work schedules were found. Most used 2 shifts/day and fewer than 24 scheduled work hours/day. On average, the late shift crew was half the size of the night shift crew as a result of reduced operational activities scheduled for work after dark.

Review of existing literature and the findings of the interviews resulted in some recommendations for implementing extended working hours. Some of the recommendations include:

- $\quad$ scheduling rest breaks and encouraging workers to try seated exercises during long shifts may help reduce the physical impact of long shifts;

- if scheduling fewer than 24 hour/day, ending the work schedule by 0100 may contribute to the success of implementing extended working hours;

- $\quad$ hiring interviews should include questions to help determine whether the applicant has personality traits that may be more suited to late shift assignments;

- trying different sleep schedules may help workers adjust to the late shift;

- permanent shift assignments, with flexibility to change shifts between employees, may help reduce the social impacts of extended work schedules and help reduce employee turnover; and

- safety plans should be updated to include increased communications between machine operators on the late shift.

Results of this study may be of value to those logging business owners that are considering changing from a traditional schedule to extended working hours, or the results may be helpful to those already implementing shift work. Additional research is needed to determine the physiological, psychological and performance impacts of shift work on forest workers. For example, additional research may help identify preferred lighting options for a variety of equipment types to aid in reducing worker fatigue.

\section{Acknowledgements}

Thank you to the Wood Supply Research Institute (www.wsri.org) for funding this project.

\section{References}

APTA. 2008. In-flight fitness. Alexandria, VA. American Physical Therapy Association. Available at: http://www.apta.org. Accessed 28 August 2008. 
Berger, C. 2003. Mental stress on harvester operators. In: Proc. of the Austro 2003 Meeting. Limbeck-Lilienau, Steinmüller and Stampfer, eds. Schlaegl, Austria. 10p.

Burgess, H. J., K. M. Sharkey, and C. I. Eastman. 2002. Bright light, dark and melatonin can promote circadian adaptation in night shift workers. Sleep Medicine Reviews 6(5): 407420.

Demerouti, E., S. A. E. Geurts, A. B. Bakker, and M. Euwema. 2004. The impact of shiftwork on work-home conflict, job attitudes and health. Ergonomics 47(9): 987-1002.

Furnham, A., and K. Hughes. 1999. Individual difference correlates of nightwork and shift-work rotation. Personality and Individual Differences 26: 941-959.

Kirk, P. 1998. The impact of shift length on processor operator fatigue. LIRO 23(18). Rotorua, New Zealand: Logging Industry Research Organisation.

Levin, L., J. Oler, and J. R. Whiteside. 1985. Injury incidence rates in a paint company on rotating production shifts. Accident Analysis and Prevention 17(1): 67-73.

Mitchell, D., and Gallagher, T. 2005. Physiological and psychological impacts of extended work hours in logging operations. ASABE Paper No. 075011. St. Joseph, Mich.: ASABE.

Nag, P. K., and V. G. Patel. 1998. Work accidents among shiftworkers in industry. International Journal of Industrial Ergonomics 21: 275-281.

Ohayon, M. A., P. Lenoine, V. Arnaud-Briant, and M. Dreyfus. 2002. Prevalence and consequences of sleep disorders on a shift worker population. Journal of Psychosomatic Research (2003) 53: 577-583.

Penkala, D. 1994. Do night shifts encounter more perils because safety works only nine-to-five? Occupational Health and Safety 63(3): 60-62.

Santhi, N., J. F. Duffy, T. S. Horowitz, and C. A. Czeisler. 2005. Scheduling of sleep/darkness affects the circadian phase of night shift workers. Neuroscience Letters 384: 316-320.

Sullman, M., and P. Kirk. 1998. Mental workload of mechanized processing with a single grip harvester. LIRO Report 23(17). Rotorua, New Zealand: Logging Industry Research Organisation. 